\title{
Attitudes towards Communication Skills among Engineering Students
}

\author{
Mirjana M. Kovac ${ }^{1} \&$ N. Sirkovic ${ }^{2}$ \\ ${ }^{1}$ Faculty of Electrical Engineering, Mechanical Engineering and Naval Architecture, University of Split, Split, \\ Croatia \\ ${ }^{2}$ Faculty of Electrical Engineering, Mechanical Engineering and Naval Architecture, University of Split, Split, \\ Croatia \\ Correspondence: Mirjana M. Kovac, FESB, Rudjera Boskovica 32, 21000 Split, Croatia. Tel: 00385-91430-5715. \\ E-mail: mirjana.kovac@fesb.hr
}

Received: November 28, 2016

Accepted: February 8, 2017 Online Published: February 10, 2017

doi: 10.5539/elt.v10n3p111

URL: http://doi.org/10.5539/elt.v10n3p111

\begin{abstract}
Good communication skills are of utmost importance in the education of engineering students. It is necessary to promote not only their education, but also to prepare them for the demanding and competitive job market. The purpose of this study was to compare the attitudes towards communication skills after formal instruction between the students of engineering studies in the first and sixth semesters. Data were collected using the Communication Skills Attitude Scale (CSAS) which consisted of 14 items. The target population included 31 students of engineering studies who attended the communication skills course in the first semester, and 31 students of engineering studies who attended the same course just before the completion of the undergraduate study programme. The results are in accordance with previous studies suggesting that senior and more mature students have higher positive attitudes compared to the students at the beginning of their undergraduate studies. Although both groups had noticeable positive attitudes towards learning communication skills, negative attitudes should also be taken into consideration and an attempt should be made to decrease them.
\end{abstract}

Keywords: communication skills, engineering student attitudes, soft skills

\section{Introduction}

Today's job market has become significantly competitive and in order to be successful the candidates must have qualities that distinguish them from other candidates with similar qualifications. Engineering graduates need communication skills to maintain relevance with the global environment. These skills are one of the 11 key outcomes required by the undergraduate engineering programme in the ABET Engineering Criteria (Baum, 2000). Extensive research on communication skills reported that inadequate and poor communication skills have a significantly negative influence on the individual and his/her profession. Therefore, communication skills should be fostered in engineering education, since the students will acquire skills needed in the profession and these courses should be part of any tertiary education (Beder, 2000).

Pollack-Wahl (2000) concluded that oral communication and presentation skills are considered one of the best career enhancers and to have the largest influence in determining a student's career success or failure. Schulz (2008) discussed how soft skills complement hard skills which are the technical requirements of a job a student is trained to perform. The author suggested that it is of great importance for every student to acquire adequate skills beyond academic or technical knowledge. Soft skills refer to communication skills, critical and structured thinking, problem solving skills, creativity, self-esteem, empathy, business management, and many other skills connected with personal traits. The importance of soft skills is becoming increasingly recognized by employers who very often complain about the lack of these skills among graduates from tertiary education institutions. In their view, the candidates have sufficient technical knowledge but lack soft skills, communication skills in particular. This requirement was noticed more than 40 years ago when the German Engineering Association recommended that $20 \%$ of all courses of the engineering curricula should include soft skills such as the knowledge of foreign languages, cultural awareness, communication skills and rhetoric courses (Ihsen, 2003).

The engineering curriculum is designed to prepare undergraduate students to become professionals in the field of engineering. However, unfortunately, written and oral skills have often been neglected, so today there are many engineers who have excellent practical knowledge but who lack communication skills. Börstler and Johansson 
(1998) claimed that computer science curricula pay little attention to the development of communication skills. But, in their view, such courses are very important to prepare students for their final thesis and professional careers. In the experience of Surratt (2006), the oral and written communication skills of first-year pharmacy graduate students are suboptimal. Students possess mediocre oral presentation skills and perhaps even worse writing skills. Holiday-Goodman et al. (1994) observed that the lack of writing skills is not solely the problem of pharmacy education because other disciplines reported similar deficiencies in critical reading and writing skills. Therefore, faculties are encouraged to incorporate more writing into their curricula. Surratt (2006) pointed out that obtaining formal presentation and writing skills could be the most important aspect of graduate student education. When asked which qualities were most important for obtaining employment, graduate business students ranked "communication skills" first, above "graduate qualities" which included "problem solving", "ability to work collaboratively" and "body of knowledge" (Feast, 2001).

Cass and Fernandes (2008) attempted to improve students' attitudes towards communication skills, since students in technology-focused fields often have an aversion to learning communication skills. In Hynes' (2012) research sixty senior managers across the corporation were interviewed to determine the most important IT training needs. Virtual face-to-face meetings, formal presentations, team skills, interpersonal communication were included. The results showed that interpersonal communication appeared to be as important as business writing and delivering professional presentations.

Ihmeideh et al. (2010) found that senior students have higher positive and lower negative attitudes towards communication skills than sophomore and junior students. Also, Rees and Garrud (2001) reported that mature students had high positive attitudes towards communication skills training. Tanyel and Mitchell (1999) argued that the communication abilities required in the professional world include written and oral communication, team skills, presentation, cultural awareness and interpersonal communication skills. Furthermore, SCANS (2000) found that interpersonal and basic communication skills including writing and speaking are highly desirable for the success in the workplace. Interpersonal communication skills refer to the ability of an individual to be effective in teams, to be able to lead, negotiate, resolve conflict situations and work efficiently with people from different cultural backgrounds.

Overall, employers in many professional fields pay more attention to the communication skills of their potential employees than to their technical skills (e.g. California State University, 2000; Reinsch and Shelby, 1997). The most required communication skill, identified as the most important competency in evaluating entry-level job candidates, is oral communication (Maes et al., 1997). However, despite the well documented need to improve communication and soft skills in general, researchers reported significant deficiencies in employees' communication skills, particularly in the case of engineering graduates compared to Humanities and Arts graduates (Schwanitz, 1999). Kane's (1993) survey of MBA recruiters for Fortune 500 companies found that recruiters focused on communication skills as the most important skill, being even more important than technical knowledge. Recruiters' most important criteria for selecting candidates for management positions were strong interpersonal skills, communication skills and team-oriented skills. Therefore, Krapels and Davis (2000) suggested communication skills courses to enhance students' communication skills, which would help companies reduce their training costs.

In conclusion, researchers and feedback from the job market emphasize the importance of excellent communication skills that are becoming increasingly important for personal as well as for professional success.

\section{Method}

The purpose of this study was to compare the attitudes towards communication skills after formal instruction between the students in the first and sixth semesters of engineering studies. Specifically, the following research questions were included in this study:

1) What are the attitudes towards communication skills of the students of engineering studies in the first and sixth semesters, that is, between students who have just enrolled in the first semester and the students who are about to obtain their Bachelor's degree and will enter the job market soon?

2) Are there significant differences in the positive and negative attitudes towards communication skills between these two groups?

The target population included 31 students of engineering studies who attended the communication skills course in their first semester of academic year 2014/2015, and 31 students of engineering studies who attended the same course in the sixth semester, that is, in the final semester before the completion of the undergraduate study programme. 
The attitudes towards learning communication skills were assessed by the Communication Skills Attitude Scale (CSAS) (Rees and Sheard, 2002; Rees and Sheard, 2003; Harlak, Dereboy and Gemalmaz, 2008). The Communication Skills Attitude Scale was taken to gather information on students' attitudes towards communication skills training. The scale (CSAS) included 14 items as presented in Table 1, ten of them were formed as positive statements, whereas four were negative statements. Each statement is accompanied by a 5-point Likert scale ranging from 1 (strongly disagree) to 5 (strongly agree). The positive attitude scale (PAS) included items $1,3,4,5,7,8,9,10,12,14$, and 2, 6, 11, 13 related to negative attitudes towards communication skills such as "I don't see the point in studying communication skills".

Table 1. Questionnaire on communication skills attitudes

\begin{tabular}{ll}
\hline No. & Item \\
\hline 1. & I need to have good communication skills if I intend to become a successful engineer. \\
2. & I don't see the point in studying communication skills. \\
3. & Communication skills (soft skills) are as important as technical skills (hard skills). \\
4. & My self-esteem has increased after attending the course. \\
5. & My presentation skills have significantly improved after the completion of the course. \\
6. & I don't have enough time to study communication skills. \\
7. & The Communication skills course is very interesting. \\
8. & I am aware of my communication skills. \\
9. & I pay more attention to my body language after the completion of the course. \\
10. & I pay more attention to fillers in my speech after the completion of the course. \\
11. & Psychology students should study communication skills, not engineers. \\
12. & It is difficult for me to admit my own communication problems. \\
13. & Communication skills is an unnecessary course. \\
14. & Communication skills can be mastered through formal instruction. \\
\hline
\end{tabular}

The questionnaire was administered to the students at the end of the teaching programme and the students were instructed how to complete the questionnaire. The questionnaire took approximately 15 minutes to complete.

\section{Results and Discussion}

The means and standard deviations (SD) related to the students in the first and sixth semesters ( 31 of them in each group) concerning both positive and negative attitude items are presented in Table 2. As can be seen, the students in the sixth semester have a higher mean value of the positive attitude items (4.016 vs 3.726), as well as a lower value of the negative ones (1.653 vs 2.024). The data are either sampled from the same population and, consequently, the differences between the sample means arise only by chance, or the differences occur because the data are taken from different populations.

The dilemma is solved using the non-parametric Mann-Whitney test, since the Likert scale refers to ordinal data. This kind of data are efficiently handled using the non-parametric tests in general. The Mann-Whitney test compares two unpaired groups, that is, the first semester and the sixth semester student data, respectively. The results of the Mann-Whitney non-parametric test are given in Table 3. 
Table 2. Means and standard deviations of the groups

\begin{tabular}{lllll}
\hline & \multicolumn{2}{c}{ First semester students } & \multicolumn{2}{c}{ Sixth semester students } \\
& Mean & SD & Mean & SD \\
\hline $\begin{array}{l}\text { Positive } \\
\text { atitude } \\
\text { items }\end{array}$ & 3.726 & 1.017 & 4.016 & 0.997 \\
$\begin{array}{l}\text { Negative } \\
\text { atitude } \\
\text { items }\end{array}$ & 2.024 & 0.841 & & 0.776 \\
\hline
\end{tabular}

Table 3. The Mann-Whitney test for positive and negative attitude items

\begin{tabular}{llll}
\hline Mann-Whitney test & $\mathbf{U}$ & $\mathbf{p}$ value & $\begin{array}{l}\text { Significant } \\
\text { difference }\end{array}$ \\
\hline Positive attitude items & 39381 & $<0.0001$ & Yes \\
Negative attitude items & 5683 & 0.0001 & Yes \\
\hline
\end{tabular}

Significant differences are obtained for both the positive and the negative attitude items. Obviously, the students in the sixth semester have gained an additional awareness during their university education regarding the significance of communication skills. A deeper insight into the differences related to each item can be obtained via a corresponding item analysis. The means and the standard deviations referring to each item are shown in Table 4.

Once more, to investigate the significant differences, the Mann-Whitney non-parametric test is employed, Table 5. As can be noticed, the significant differences between the first group and the second group are obtained for items $1,2,3,10$, and 11 , respectively.

The first two items "I need to have good communication skills if I intend to become a successful engineer", and "Communication skills (soft skills) are as important as technical skills (hard skills)" have been recognized by the students in the sixth semester because they will soon finish their undergraduate education and have already faced many situations where they had to show good communication skills such as teamwork with colleagues, formal communication with their teachers, oral presentations, oral exams, and the like. Also, some of them are already investigating the job market which requires specific communication skills. On the other hand, the students in the first semester have just started their tertiary education and are more occupied with vocational subjects and do not think about what follows afterwords. In many cases their self-esteem is low when it comes to courses requiring good knowledge of technical subjects. They are mostly concerned with passing "difficult" exams, trying to overcome difficulties connected with vocational courses. This is supported by the following statements: "I don't see the point in studying communication skills" and "Psychology students should study communication skills, not engineers". First-year students do not pay sufficient attention to this aspect of education, thinking that communication skills can easily be obtained afterwords. The item "I pay more attention to fillers in my speech after the completion of the course" has been recognized by the students in the sixth semester more than by their peers in the first semester. The former already know how important it is to have fluent speech, and that fillers negatively influence the overall performance when it comes to evaluating presentations and oral exams. Older and more mature students are aware of the necessity of flawless speech and good communication skills in general. 
Table 4. Means and standard deviations for each item

\begin{tabular}{lllll}
\hline $\begin{array}{llll}\text { Item } \\
\text { number }\end{array}$ & $\begin{array}{l}\text { First semester students } \\
\text { Mean }\end{array}$ & SD & Sixth semester students \\
\hline 1. & 4.129 & 0.670 & Mean & SD \\
2. & 1.839 & 0.638 & 4.677 & 0.475 \\
3. & 3.065 & 1.063 & 1.355 & 0.486 \\
4. & 3.839 & 0.688 & 3.774 & 0.845 \\
5. & 4.097 & 0.539 & 4.000 & 0.633 \\
6. & 2.548 & 0.925 & 3.968 & 0.752 \\
7. & 4.194 & 0.703 & 2.226 & 0.921 \\
8. & 3.774 & 1.023 & 4.452 & 0.624 \\
9. & 3.871 & 1.088 & 4.161 & 0.820 \\
10. & 3.839 & 0.779 & 4.290 & 0.6923 \\
11. & 2.129 & 0.806 & 4.452 & 0.624 \\
12. & 2.194 & 0.833 & 1.645 & 0.798 \\
13. & 1.581 & 0.672 & 2.129 & 0.922 \\
14. & 4.258 & 0.729 & 1.387 & 0.495 \\
\hline
\end{tabular}

Table 5. The Mann-Whitney test for each item

\begin{tabular}{llll}
\hline Mann-Whitney test & U & p value & Significant difference \\
\hline Item number & & & \\
1. & 264 & 0.0012 & Yes \\
3. & 288 & 0.0024 & Yes \\
4. & 298 & 0.0069 & Yes \\
5. & 407.5 & 0.2419 & No \\
6. & 443 & 0.5470 & No \\
7. & 365.5 & 0.0850 & No \\
8. & 385.5 & 0.1623 & No \\
9. & 370.5 & 0.1008 & No \\
10. & 385 & 0.1578 & No \\
11. & 268 & 0.0012 & Yes \\
12. & 317 & 0.0142 & Yes \\
13. & 445.5 & 0.5979 & No \\
14. & 412.5 & 0.2734 & No \\
\hline
\end{tabular}

\section{Conclusion}

Good communication skills are very important in the education of engineering students to prepare them for the demanding and competitive job market. The results of this study revealed that there were significant differences between the two groups of participants in their positive as well as negative attitudes towards communication skills. The results are in accordance with previous studies suggesting that more mature students have higher positive attitudes and lower negative attitudes towards communication skills compared to students at the beginning of their undergraduate studies (Shankar et al., 2010; Ihmeideh et al., 2010; Rees \& Garrud, 2001). 
Also, they reported that more mature students had high positive attitudes towards communication skills training. In this survey, students in the first and sixth semesters have perceived the importance of good communication skills, and high positive attitudes have been found after formal training regarding, for instance, formal presentations, and according to the statements, their self-esteem has increased after attending the course.

Though positive attitudes dominate, negative attitudes should not be overlooked. Negative attitudes such as "I don't see the point in studying communication skills", if not supervised, might have negative impact on positive attitudes. However, students in the sixth semester are more aware of the necessity of good communication skills, which they have already practiced through formal presentations, teamwork, oral exams and written formal communication.

Besides raising awareness about the importance of communication skills among students at any level of education and encouraging them to improve their skills, it would be recommended to place greater importance on communication skills at the beginning of university education, as well as to provide more opportunities for students to learn and practice them.

\section{References}

Baum, E. (2000). Engineering accreditation in the Unites States of America - Criteria 2000. Proceedings 2nd Global Congress on Engineering Education, Wismar, Germany, 17-20.

Beder, S. (2000). Valuable skills learned from basket weaving. Engineers Australia, 46.

Börstler, J., \& Johansson, O. (1998). The students conference - a tool for teaching of research, writing, and presentation skills. SIGSCE Bulletin, 30(3), 28-31. https://doi.org/10.1145/290320.283007

California State University (2000). Employers' demand for skills. Online: www.des.can.com/commercial/ construction/industry-trends.

Cass, A., \& Fernandes, C. (2008). Simulated conference submissions: A technique to improve student attitudes about writing. $38^{\text {th }}$ ASEE/IEEE Frontiers in Education Conference, Session S3F, Saratoga Springs, USA, 15-20. https://doi.org/10.1109/fie.2008.4720357

Feast, V. (2001). Student perceptions of the importance and value of a Graduate Quality framework in a tertiary environment. International Education Journal, 2(4), 144-158.

Harlak, H., Dereboy, C., \& Gemalmaz, A. (2008). Validation of a Turkish translation of the communication skills attitude scale with Turkish medical students. Education Health, 21(1).

Holiday-Goodman, M., Lively, B. T., Nemire, R., \& Mullin, J. (1994). Developing of a teaching module on written and verbal communication skills. American Journal of Pharmaceutical Education, 58, 257-261.

Hynes, G. E. (2012). Improving employees' interpersonal communication competencies: A qualitative study. Business Communication Quarterly, 75(4), 466-475. https://doi.org/10.1177/1080569912458965

Ihmeideh, F. M., Al-Omari, A. A., \& Al-Dababneh, K. A. (2010). Attitudes toward communication skills among students'-teachers' in Jordanian public universities. Australian Journal of Teacher Education, 35(4), 1-11. https://doi.org/10.14221/ajte.2010v35n4.1

Ihsen, S. (2003). Gefragt: Tuftle und Rede! ZEIT Chancen, 18, 24, Germany: ZEIT Verlag.

Kane, K. F. (1993). MBAs: A recruiter's eye-view. Business Horizons, 36(1), 65-71. https://doi.org/10.1016/s0007-6813(05)80106-5

Krapels, R. H., \& Davis, B. D. (2000). Communication training in two companies. Business Communication Quarterly, 63(3), 104-110. https://doi.org/10.1177/108056990006300312

Maes, J. D., Weldy, T. G., \& Icenogle, M. L. (1997). A managerial perspective: Oral communication competency is most important for business students in the workplace. Journal of Business Communication, 34(1), 67-80. https://doi.org/10.1177/002194369703400104

Pollack-Wahl, J. A. (2000). It is time to stand up and communicate. Proceedings 30th ASEE/IEEE Frontiers in Education Conference, Kansas City, USA, FIG-16-FIG-21.

Rees, C., \& Garrud, P. (2001). Identifying undergraduate medical students' attitudes toward communication skills learning: A pilot study. Medical Teacher, 23(4), 400-406. https://doi.org/10.1080/01421590120057067

Rees, C., \& Sheard, C. (2002). The relationship between medical students' attitudes towards communication skils learning and their demographic and education-related characteristics. Medical Education, 36(11), 1017-1027. https://doi.org/10.1046/j.1365-2923.2002.01333.x 
Rees, C., \& Sheard, C. (2003). Evaluating first-year medical students' attitudes to learning communication skils before and after a communication skills course. Medical Teacher, 25(3), 302-307. https://doi.org/10.1080/0142159031000100409

Rees, C., Sheard, C., \& Davies, S. (2002). The development of a scale to measure medical studnets' attitudes towards communication skills learning: the Communication Skills Attitude Scale (CSAS). Medical Education, 36, 141-147. https://doi.org/10.1046/j.1365-2923.2002.01072.x

Reinsch, L. N., \& Shelby, A. N. (1997). What communication abilities do practitioners need? Evidence from $\begin{array}{lllll}\text { MBA students. Business Communication } & \text { Quaerterly, }\end{array}$ https://doi.org/10.1177/108056999706000401

SCANS report for America 2000. Washington, D.C.: U.S. Department of Labor.

Schulz, B. (2008). The importance of soft skills: Education beyond academic knowledge. Journal of Language and Communication, 2(1), 145-154.

Schwanitz, D. (1999). Bildung. Frankfurt am Main: Eichborn.

Shankar, P. R., Dubey, A. K., Balasubramanium, \& Dwivedi, N. R. (2013). Student attitude towards communication skills learning in a Caribbean medical school. Australasian Medical Journal, 6(9), 466-475.

Surrat, C. K. (2006). Instructional design and assessment - Creation of a graduate oral/written communication skills course. American Journal of Pharmaceutical Education, 70(1), 1-8. https://doi.org/10.5688/ aj700105

Tanyel, F., \& Mitchell, M. (1999). The skill set for success of new business school graduates: Do perspective emloyers and university faculty agree? Journal of Education for Business, 75, 33-38. https://doi.org/10.1080/08832329909598987

\section{Copyrights}

Copyright for this article is retained by the author(s), with first publication rights granted to the journal.

This is an open-access article distributed under the terms and conditions of the Creative Commons Attribution license (http://creativecommons.org/licenses/by/4.0/). 